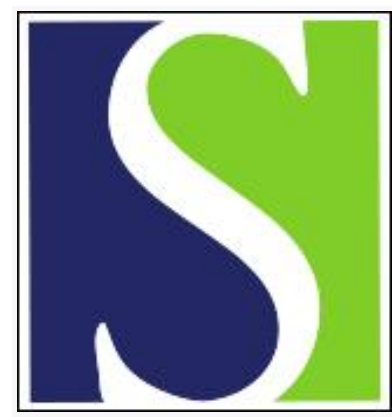

Scand J Work Environ Health 2009;35(5):325-333

https://doi.org/10.5271/sjweh.1340

Published online: 23 Jun 2009, Issue date: 00 Oct 2009

Impact of work-related factors, lifestyle, and work ability on sickness absence among Dutch construction workers

by Alavinia SM, van den Berg TIJ, van Duivenbooden C, Elders LAM, Burdorf A

Affiliation: Department of Public Health, Erasmus MC, University Medical Center Rotterdam, Rotterdam, the Netherlands

Refers to the following texts of the Journal: 2006;32(1):75-84

2007;33(5):351-357 2006;32(4):253-255 1997;23 suppl 1:7-11

2007;33(3):233-239

The following articles refer to this text: 2009;35(5):321-324; 2010;36(5):404-412; 2010;36(6):515-516; 2011;37(6):455-463; 2011;37(6):451-453; 2012;38(6):600-603; 2013;39(5):456-467; 2014;40(1):82-88; 2014;40(3):278-286; 2014;40(3):244-251; 2015;41(1):36-42; 2015;41(3):322-323; 2015;41(4):397-406; 2020;46(1):5-18

Key terms: construction; construction worker; Denmark; individual characteristic; lifestyle; sick leave; sickness absence; WAl; work ability; work ability index; work factor; work-related factor

This article in PubMed: www.ncbi.nlm.nih.gov/pubmed/19554244

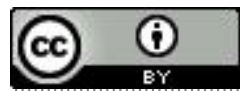




\title{
Impact of work-related factors, lifestyle, and work ability on sickness absence among Dutch construction workers
}

\author{
by Seyed M Alavinia, PhD, ${ }^{1}$ Tilja IJ van den Berg, MSc, ${ }^{1}$ Cor van Duivenbooden, MD, ${ }^{2}$ Leo AM Elders, \\ $\mathrm{PhD},{ }^{1}$ Alex Burdorf, $\mathrm{PhD}^{1}$
}

\begin{abstract}
Alavinia SM, van den Berg TIJ, van Duivenbooden C, Elders LAM, Burdorf A. Impact of work-related factors, lifestyle, and work ability on sickness absence among Dutch construction workers. Scand J Work Environ Health. 2009;35(5):325-333.
\end{abstract}

Objective The objective of this study was to evaluate the relative contribution of individual characteristics, lifestyle factors, work-related risk factors, and work ability on the occurrence of short $(<2$ weeks), moderate (2-12 weeks), and long (>12 weeks) durations of sickness absence.

Methods Altogether, 5867 Dutch construction workers with complete sick leave registration were followed from the day of their medical examination in 2005 until the end of 2006. The main outcome of the study was the duration of sickness absence, as registered by an occupational health service. Independent variables consisted of individual characteristics, lifestyle factors, work-related factors, and the work ability index. We used Poisson regression analyses with repeated occurrence of sick leave to calculate rate ratios (RR) and $95 \%$ confidence intervals of independent variables for the three categories of sick leave duration.

Results Predictors for sick leave lasting 2-12 weeks and $>12$ weeks were: older age, obesity, smoking, manual materials handling, lack of job control, lung restriction, and a less-than-excellent work ability. For most predictors, higher RR values were observed with a longer duration of sickness absence. Obesity, smoking, manual materials handling, and lack of job control remained important risk factors for moderate and long durations of sick leave after adjusting for the strong effects of work ability on sickness absence. The highest populationattributable fractions were observed for: age over 50 years (18\%), manual materials handling (20\%), and good $(18 \%)$, moderate $(28 \%)$, and poor ( $2 \%)$ work ability.

Conclusion This study suggests that a variety of preventive measures targeted at smoking, obesity, physical load, psychosocial work factors as well as work ability will contribute to a reduction in the occurrence of sick leave.

Key terms individual characteristic; sick leave; work ability index; WAI; work factor.

Sickness absence is an expression of the complex relation between health and work characteristics (1) and is thought to have a multifactorial etiology (2). A range of factors can influence the occurrence and duration of sickness absence such as individual characteristics, health behavior, and work-related factors $(2-5)$. Older workers take sick leave less often, but their periods of absence are generally longer than younger workers (69). Labriola et al have shown that obesity, smoking, and poor health are associated with sickness absence (10). In general, blue-collar workers take more sick leave than their white-collar counterparts, both more often and for a longer period of time $(3,9,11,12)$. Sickness absence is also related to high physical and psychosocial demands at work, especially low decision authority and job control $(2,13,14)$.

There is ample evidence that construction workers have a higher risk of health problems that may lead to sickness absence and subsequent work-related disability $(15,16)$. A prospective study among construction workers showed that physical load was a risk factor for sickness absence (17). The high physical load in the construction industry is largely determined by manual materials handling and repetitive, awkward postures $(15,18)$.

The work ability index (WAI) has been promoted in recent years as a valuable tool in occupational health programs aimed at decreasing the number of early exits from the workplace (19). Although the relationship

1 Department of Public Health, Erasmus MC, University Medical Center Rotterdam, Rotterdam, the Netherlands.

2 Arbouw Foundation, Amsterdam, the Netherlands.

Correspondence and reprints to: Dr A Burdorf, Department of Public Health, Erasmus MC, PO Box 2040, 3000 CA Rotterdam, the Netherlands. [E-mail: a.burdorf@erasmusmc.nl] 
between work-related factors, individual health, and the WAI is well known (20), there is limited information on its predictive value for future sickness absence. A study by Kujala et al showed that a decreased work ability among young employees had a predictive value for long-term sickness absence (21).

The aim of our study was to evaluate the relative impact of individual characteristics, lifestyle factors, work-related risk factors, and work ability on the occurrence of short, moderate, and long spells of sickness absence among Dutch construction workers.

\section{Material and methods}

\section{Study population and design}

The study population consisted of workers in the construction industry in the Netherlands who participated in a voluntary medical examination in 2005. Such examinations are offered to all construction workers at least every four years. The Arbouw Foundation, responsible for the organization and contracting of the examinations, estimates that the annual participation is about $60 \%$ of all invited construction workers. In the Netherlands, the periodic examination is offered by over 20 different occupational health services with local branches and consists of a questionnaire and physical examination. Of the 19753 examined workers, registration of sickness absence and complete questionnaire data were available for 5867 male workers from one large occupational health service. Given the very small number of female workers $(\mathrm{N}=245)$, the analysis was limited to male construction workers. Sickness absence registration for other workers was either done by the construction companies themselves, incomplete, or unavailable for analysis. The workers were followed from the day of their medical examination until the end of 2006. The mean follow-up time was 437 days, with a minimum of 374 days and a maximum of 699 days.

\section{Sickness absence}

During the follow-up period, the sickness absence register was maintained by the occupational health service, which recorded the occurrence and duration of every absence episode. The primary measure of interest was the duration of the sickness absence period during the follow-up, which was categorized as being of short ( $<14$ days), moderate (2-12 weeks), and long $(>12$ weeks) duration. In the Netherlands, in almost all situations, a worker will be paid a full salary during the first year of sickness absence; a worker is not eligible for a permanent disability pension during the first two years on sick leave. Six weeks after the first day of sick leave, the law requires that the worker and employer agree upon a written rehabilitation plan.

\section{Work-related factors}

The work-related factors in the questionnaire consisted of physical and psychosocial items. Ascertained by dichotomized questions (19), physical load referred to the regular presence in the current job of manual materials handling, awkward back postures, static work postures, repetitive movements, whole body vibration, and hand-arm vibration. Psychosocial work characteristics of the job were assessed with an abbreviated Dutch version of Karasek's job content questionnaire (22), which included two "yes or no" questions on job demands and control. In addition, there were dichotomized questions on supervisor and co-worker support, and job satisfaction (19).

\section{Individual characteristics and lifestyle factors}

Information on age, height, weight, and type of job were collected during the medical examination. The body mass index (BMI) was calculated by dividing body weight in kilograms by the square of body height in meters, and used to define subjects as normal $\left(<25 \mathrm{~kg} / \mathrm{m}^{2}\right)$, overweight $\left(25-30 \mathrm{~kg} / \mathrm{m}^{2}\right)$, or obese $\left(>30 \mathrm{~kg} / \mathrm{m}^{2}\right)$. The lifestyle factors of interest included smoking, alcohol consumption, and physical activity during leisure time. Subjects were classified as current smokers or non-/exsmokers. An open question on the average number of alcoholic drinks consumed per week was used to define problematic alcohol use as the consumption of 15 units of alcohol or more per week (23). Physical activity during leisure time was addressed by a single open question on the frequency of physical activity for at least $30 \mathrm{~min}$ utes per day and a single question, with 5 answer categories, on the frequency of strenuous (sweat-inducing) physical activity. Those who reported being physically active for 30 minutes per day, at least 5 days a week, were considered to be doing moderately intense physical activity. Subjects doing vigorous exercises at least 3 times per week were considered to be doing vigorously intense physical activity (24).

\section{Health}

Total blood cholesterol and high-density lipoprotein cholesterol were measured in venous blood samples. Spirometry was conducted to measure forced expiratory volume $\left(\mathrm{FEV}_{1}\right)$ and forced vital capacity $(\mathrm{FVC})$. The $\mathrm{FEV}_{1}$ and $\mathrm{FVC}$ were expressed as percentages of the predicted values, based on reference equations (25). According to the spirometry findings, workers were 
divided into normal, obstructive, and restrictive lung diseases, in line with the American Thoracic Society criteria (26). The age, total blood cholesterol, highdensity lipoprotein cholesterol, smoking habits, and systolic blood pressure of each participant were used to calculate the Framingham Risk Score for the 10-year risk of coronary heart disease events (coronary heart disease death and myocardial infarction) (27). The 10 -year risk prediction was dichotomized into "no risk" $(0-9 \%)$, and "cardiovascular risk" (more than 10\%) of coronary heart death and myocardial infarction (28).

\section{Work ability}

Work ability was measured by the WAI questionnaire consisting of an assessment of seven dimensions: an individual's (i) physical and (ii) mental demands in relation to his work, (iii) diagnosed diseases, (iv) experienced limitations in work due to disease, (v) occurrence of sick leave in the previous 12 months, (vi) work ability prognosis, and (vii) mental resources. The WAI index is derived as the sum score of the ratings on each dimension. The range of the summative index is $7-49$, which is classified into "poor" (7-27), "moderate" (28-36), "good" (37-43), and "excellent" (44-49) work ability (29).

\section{Statistical analysis}

All descriptive data are presented as mean and standard deviation, or percentage when appropriate. The dependent variable in the statistical analysis was the duration of sickness absence during the follow-up, categorized as being of short, moderate, or long duration. For each duration of sickness absence, we used "workers without sick leave" as the reference group. Since Poisson regression analysis is a robust method when there is a slight variation in the occurrence of events over the follow-up time and the event of interest is less common (eg, long duration sick leave) $(30,31)$, we used a Poisson regression analysis with repeated occurrence of sickness absence. This approach yields effect estimates that are referred to as rate ratios (RR). The follow-up time was defined by the actual time at risk and, thus, was restricted to the first day of sickness absence. In case of multiple sickness absence periods, the follow-up time was calculated from the first day of return to work until the next episode of sickness absence or the end of follow-up. Since subjects were not all followed for the same period of time, the logarithm of the actual follow-up time was used as an offset variable to take the actual time at risk into account (30). In the first step of the analysis, all variables with a $\mathrm{P}$-value $<0.10$ were selected in univariate Poisson regression models with the three durations of sickness absence as dependent variables. The one-sided P-value of the Cochrane-Armitage test was used to test the hypothesis of a trend between an explanatory variable and the dependent variable. Subsequently, we used a backward selection procedure to retain important variables with a significant effect $(\mathrm{P}<0.05)$ in the final multivariate Poisson regression models, with the significance level evaluated by the scaled deviance between the full model and the reduced model. In order to make comparisons across the three durations of sick leave, variables with a significant $R R$ in one model were included in another model, regardless of their level of significance in that model. All analyses were carried out with the statistical package SAS version 9.13 (SAS institute, Cary NC, USA).

\section{Results}

Table 1 describes the baseline characteristics of the study population in the construction industry in the Netherlands, stratified by the longest duration of sickness absence during follow-up. The mean age of the workers was 44 years [standard deviation (SD) 11], ranging from 16-62 years. Most workers held a blue-collar job (77.4\%). The mean BMI for the study population was 26.2 (SD 3.6); $47.4 \%$ were overweight and $13.0 \%$ were obese. The distribution of excellent, good, moderate, and poor work ability was $33.0 \%, 50.2 \%, 15.6 \%$, and $1.2 \%$, respectively. Among the 5867 workers, 1981 (34\%) workers had at least one episode of sickness absence, with a total of 2544 periods of short duration, 614 periods of moderate duration, and 152 periods of long duration. The analyses of trends showed that a higher BMI, smoking, poor health, higher physical and psychosocial load at work, and lower work ability at baseline were increasingly prevalent among workers with a longer duration of sickness absence during follow-up.

Table 2 shows the influence of individual characteristics, lifestyle factors, health indicators, and the WAI on sickness absence in the univariate Poisson regression analyses. White-collar workers had consistently a lower risk of sick leave compared with blue-collar workers. The RR increased by the category of duration of sickness absence for: older age, overweight, obesity, problematic alcohol use, lung obstruction, lung restriction, and a moderate WAI.

Table 3 describes the univariate associations between work-related factors and sick leave. The physical workrelated factors were associated with short, moderate, and long spells of sickness absence. For most physical risk factors, the observed RR were higher for moderate and long durations of sickness absence than for short spells. Among the psychosocial factors, high work demands were not associated with the occurrence of sick leave. For most psychosocial risk factors, larger RR were found with a longer duration of sick leave. 
Table 1. Baseline characteristic of individual factors, lifestyles, health indicators, work-related factors, and work ability index in a longitudinal study among 5867 male construction workers in the Netherlands. (BMI = body mass index)

\begin{tabular}{|c|c|c|c|c|c|c|c|c|c|c|c|c|}
\hline & \multicolumn{3}{|c|}{$\begin{array}{l}\text { No sickleave } \\
(\mathrm{N}=3886)\end{array}$} & \multicolumn{3}{|c|}{$\begin{array}{l}\text { Short spell of sickleave } \\
<2 \text { weeks }(N=1284)\end{array}$} & \multicolumn{3}{|c|}{$\begin{array}{l}\text { Moderate spell of sickleave } \\
2-12 \text { weeks }(\mathrm{N}=547)\end{array}$} & \multicolumn{3}{|c|}{$\begin{array}{l}\text { Long spell of sickleave } \\
>12 \text { weeks }(\mathrm{N}=150)\end{array}$} \\
\hline & Mean & SD & $\%$ & Mean & SD & $\%$ & Mean & SD & $\%$ & Mean & SD & $\%$ \\
\hline \multicolumn{13}{|l|}{ Individual characteristics } \\
\hline Age & 44.0 & 11.06 & .. & 42.4 & 11.5 &.. & 45.7 & 10.5 & .. & 47.0 & 9.8 & .. \\
\hline $\mathrm{BMI}$ a & 26.1 & 3.62 & .. & 26.0 & 3.5 &.. & 26.7 & 3.6 & .. & 27.2 & 4.3 & .. \\
\hline White-collar job a &.. & .. & 24.9 &.. & .. & 21.9 &.. & .. & 11.0 &.. &.. & 14.0 \\
\hline \multicolumn{13}{|l|}{ Lifestyle factors } \\
\hline Smoker ${ }^{\mathrm{a}}$ &.. & .. & 31.2 & .. & .. & 33.3 & .. & .. & 37.5 & .. &.. & 34.7 \\
\hline Problematic alcohol drinker & .. & .. & 14.0 &.. & .. & 12.2 & .. & .. & 16.3 & .. &.. & 16.7 \\
\hline Normal physical activity a & .. & .. & 67.9 & .. & .. & 67.8 & .. & .. & 76.2 & .. &.. & 71.4 \\
\hline Vigorous physical activity &.. & .. & 19.9 &.. & .. & 20.1 & .. & .. & 20.5 & .. &.. & 23.1 \\
\hline \multicolumn{13}{|l|}{ Health indicators } \\
\hline Lung obstruction ${ }^{\mathrm{a}}$ &.. & .. & 2.0 & .. & .. & 2.9 & .. & .. & 2.9 & .. &.. & 4.7 \\
\hline Lung restriction a & .. & .. & 0.8 & .. & .. & 1.5 & .. & .. & 1.3 & .. & .. & 3.3 \\
\hline Cardiovascular risk ${ }^{a}$ &.. & .. & 29.2 &.. & .. & 28.0 & .. & .. & 34.6 & .. &.. & 33.3 \\
\hline \multicolumn{13}{|l|}{ Work-related physical factors } \\
\hline Manual materials handling a &.. & .. & 45.1 &.. & .. & 48.1 & .. & .. & 57.6 & .. &.. & 58.7 \\
\hline Awkward back postures a & .. & .. & 21.8 & .. & .. & 26.4 & .. & .. & 33.6 & .. &.. & 33.3 \\
\hline Static work postures ${ }^{\mathrm{a}}$ &.. & .. & 34.0 &.. & .. & 37.5 & .. & .. & 46.4 & .. &.. & 44.7 \\
\hline Repetitive movement ${ }^{a}$ &.. & .. & 18.8 &.. & .. & 22.7 & .. & .. & 31.4 & .. &.. & 30.0 \\
\hline Whole body vibration a & .. & .. & 13.5 &.. & .. & 15.3 & .. & .. & 19.2 & .. &.. & 16.3 \\
\hline Hand-arm vibration ${ }^{a}$ &.. & .. & 15.2 &.. & .. & 17.9 & .. & .. & 21.9 & .. &.. & 17.6 \\
\hline \multicolumn{13}{|c|}{ Work-related psychosocial factors } \\
\hline Lack of job control a &.. & .. & 32.5 &.. & .. & 36.2 & .. & .. & 45.3 & .. &.. & 38.7 \\
\hline High work demands a &.. & .. & 58.9 &.. & .. & 61.1 & .. & .. & 62.0 & .. &.. & 60.7 \\
\hline Lack of support at work a & .. & .. & 12.1 & .. & .. & 13.5 & .. & .. & 14.6 & .. & .. & 19.1 \\
\hline Dissatisfaction with work a &.. & .. & 4.0 &.. & .. & 4.9 & .. & .. & 6.2 & .. &.. & 8.7 \\
\hline \multicolumn{13}{|l|}{ Work ability index } \\
\hline Excellent $^{\mathrm{a}}$ &.. & .. & 36.5 &.. & .. & 29.1 & .. & .. & 22.6 & .. &.. & 18.7 \\
\hline Good & .. & .. & 49.2 & .. & .. & 53.8 & .. & .. & 50.6 & .. &.. & 43.3 \\
\hline Moderate ${ }^{a}$ &.. & .. & 13.2 &.. & .. & 16.0 & .. & .. & 26.0 & .. &.. & 36.0 \\
\hline Poora &.. & .. & 1.1 &.. & .. & 1.1 & .. & .. & 1.8 & .. &.. & 2.0 \\
\hline
\end{tabular}

a Significant trend $(P<0.05)$ in Cochrane-Armitage test.

Table 4 shows that risk factors for sickness absence of $<2$ weeks were: younger age, smoking, working with awkward back postures, lack of job control, and a less-than-excellent work ability. For sick leave of 2-12 weeks, important risk factors included: older age, obesity, smoking, manual materials handling, lack of job control, lung restriction, and a reduced work ability. The risk factors for sick leave of $>12$ weeks were comparable to those of a moderate duration; however, some factors failed to reach significance due to large confidence intervals. Most of the univariate associations between lifestyle factors, physical and psychosocial work factors, and all categories of sickness absence (as observed in table 3) had substantially lower RR when adjusted for each other and the WAI. However, obesity, smoking, manual materials handling, and lack of job control remained important risk factors for moderate and long durations of sickness absence after adjustment for the other risk factors. The population-attributable fractions of significant risk factors were comparable for moderate and long durations of sickness absence, but slightly larger for the latter. A duration of sickness absence of $>12$ weeks had the highest population-attributable fractions for: age over 50 years (18\%), manual materials handling (20\%), and good (18\%), moderate (28\%), and poor $(2 \%)$ work ability.

When adjusted for individual characteristics, lifestyle factors, and work characteristics, two dimensions of the WAI were significant predictors for both moderate and long durations of sickness absence: (i) the presence of sickness absence in the past 12 months prior to the medical examination and (ii) experienced limitations due to health problems. Both WAI dimensions predicted a moderate duration of sickness absence with a RR of 1.40 (95\% CI $1.30-1.51)$ and $1.22(95 \%$ CI 1.11-1.34), respectively. The corresponding figures for a long duration of sickness absence were $1.53(95 \% \mathrm{CI}$ $1.32-1.7)$ and 1.24 (95\% CI 1.04-1.48). The presence 
Table 2. Crude rate ratios (RR) and $95 \%$ confidence intervals $(95 \% \mathrm{Cl})$ of individual and lifestyle characteristics, and health indicators for sickness absence in a longitudinal study among 5867 male construction workers in the Netherlands. $($ BMI = body mass index)

\begin{tabular}{|c|c|c|c|c|c|c|}
\hline & \multicolumn{2}{|c|}{$\begin{array}{l}\text { Short spell of sickleave } \\
<2 \text { weeks }(N=1284)\end{array}$} & \multicolumn{2}{|c|}{$\begin{array}{l}\text { Moderate spell of sickleave } \\
2-12 \text { weeks }(\mathrm{N}=547)\end{array}$} & \multicolumn{2}{|c|}{$\begin{array}{l}\text { Long spell of sickleave } \\
>12 \text { weeks }(\mathrm{N}=150)\end{array}$} \\
\hline & $\mathrm{RR}$ & $95 \% \mathrm{Cl}$ & $\mathrm{RR}$ & $95 \% \mathrm{Cl}$ & $\mathrm{RR}$ & $95 \% \mathrm{Cl}$ \\
\hline \multicolumn{7}{|l|}{ Individual characteristics } \\
\hline \multicolumn{7}{|l|}{ Age } \\
\hline$<40$ years & 1.00 & Reference & 1.00 & Reference & 1.00 & Reference \\
\hline $40-50$ years & $0.73^{a}$ & $0.64-0.84$ & $1.36^{a}$ & $1.06-1.73$ & 1.41 & $0.87-2.28$ \\
\hline$\geq 50$ years & $0.70^{\mathrm{a}}$ & $0.61-0.80$ & $1.67^{\mathrm{a}}$ & $1.32-2.10$ & $2.08^{a}$ & $1.33-3.24$ \\
\hline \multicolumn{7}{|l|}{$\mathrm{BMI}\left(\mathrm{kg} / \mathrm{m}^{2}\right)$} \\
\hline Normal weight & 1.00 & Reference & 1.00 & Reference & 1.00 & Reference \\
\hline Overweight & 0.99 & $0.88-1.11$ & 1.20 & $0.99-1.45$ & 1.34 & $0.93-1.95$ \\
\hline Obese & 0.98 & $0.82-1.17$ & $1.52^{\mathrm{a}}$ & $1.18-1.96$ & $2.06^{a}$ & $1.31-3.26$ \\
\hline White-collar job & $0.77^{\mathrm{a}}$ & $0.67-0.89$ & $0.36^{\mathrm{a}}$ & $0.27-0.47$ & $0.49^{a}$ & $0.31-0.77$ \\
\hline \multicolumn{7}{|l|}{ Lifestyle factors } \\
\hline Smoker & $1.24^{\mathrm{a}}$ & $1.10-1.39$ & $1.35^{\mathrm{a}}$ & $1.13-1.62$ & 1.18 & $0.84-1.66$ \\
\hline Problematic alcohol use & 0.98 & $0.83-1.16$ & $1.27^{\mathrm{a}}$ & $1.00-1.61$ & 1.31 & $0.84-2.04$ \\
\hline Normal physical activity & 1.05 & $0.92-1.20$ & $1.59^{a}$ & $1.27-1.99$ & 1.14 & $0.76-1.72$ \\
\hline Vigorous physical activity & 1.10 & $0.96-1.27$ & 1.06 & $0.85-1.32$ & 1.20 & $0.81-1.78$ \\
\hline \multicolumn{7}{|l|}{ Health indicators } \\
\hline Lung obstruction & $1.44^{\mathrm{a}}$ & $1.04-2.00$ & 1.68 & $0.98-2.88$ & $2.35^{a}$ & $1.08-5.11$ \\
\hline Lung restriction & $1.72^{\mathrm{a}}$ & $1.10-2.70$ & 1.48 & $0.67-3.27$ & $3.88^{\mathrm{a}}$ & $1.53-9.80$ \\
\hline Cardiovascular risk & 0.94 & $0.83-1.06$ & $1.28^{\mathrm{a}}$ & $1.07-1.54$ & 1.24 & $0.88-1.75$ \\
\hline \multicolumn{7}{|l|}{ Work ability index } \\
\hline Good & $1.46^{\mathrm{a}}$ & $1.28-1.66$ & $1.76^{\mathrm{a}}$ & $1.41-2.20$ & $1.68^{a}$ & $1.07-2.63$ \\
\hline Moderate & $2.02^{\mathrm{a}}$ & $1.71-2.38$ & $3.35^{\mathrm{a}}$ & $2.60-4.31$ & $5.15^{\mathrm{a}}$ & $3.23-8.21$ \\
\hline Poor & 1.66 & $0.96-2.89$ & $3.64^{\mathrm{a}}$ & $1.88-7.04$ & $3.58^{\mathrm{a}}$ & $1.08-11.91$ \\
\hline
\end{tabular}

a $P<0.05$

Table 3. Crude rate ratios (RR) and $95 \%$ confidence interval $(95 \% \mathrm{CI})$ of work-related factors for sickness absence in a longitudinal study among 5867 male construction workers in the Netherlands.

\begin{tabular}{|c|c|c|c|c|c|c|}
\hline & \multicolumn{2}{|c|}{$\begin{array}{l}\text { Short spell of sickleave } \\
<2 \text { weeks }(\mathrm{N}=1284)\end{array}$} & \multicolumn{2}{|c|}{$\begin{array}{l}\text { Moderate spell of sickleave } \\
2-12 \text { weeks }(\mathrm{N}=547)\end{array}$} & \multicolumn{2}{|c|}{$\begin{array}{l}\text { Long spell of sickleave } \\
>12 \text { weeks }(N=150)\end{array}$} \\
\hline & $\mathrm{RR}$ & $95 \% \mathrm{Cl}$ & $\mathrm{RR}$ & $95 \% \mathrm{Cl}$ & $\mathrm{RR}$ & $95 \% \mathrm{Cl}$ \\
\hline \multicolumn{7}{|l|}{ Work-related factors } \\
\hline \multicolumn{7}{|l|}{ Physical factors } \\
\hline Manual materials handling & $1.22^{a}$ & $1.09-1.36$ & $1.66^{a}$ & $1.39-1.98$ & $1.76^{a}$ & $1.26-2.44$ \\
\hline Awkward back postures & $1.41^{\mathrm{a}}$ & $1.25-1.60$ & $1.74^{\mathrm{a}}$ & $1.45-2.09$ & $1.73^{\mathrm{a}}$ & $1.23-2.44$ \\
\hline Static postures & $1.26^{a}$ & $1.13-1.41$ & $1.65^{\mathrm{a}}$ & $1.39-1.97$ & $1.52^{\mathrm{a}}$ & $1.10-2.11$ \\
\hline Repetitive movement & $1.42^{\mathrm{a}}$ & $1.24-1.61$ & $1.88^{a}$ & $1.56-2.27$ & $1.80^{a}$ & $1.26-2.56$ \\
\hline Whole body vibration & $1.24^{\mathrm{a}}$ & $1.06-1.45$ & $1.50^{\mathrm{a}}$ & $1.20-1.88$ & 1.23 & $0.79-1.91$ \\
\hline Hand-arm vibration & 1.29 a & $1.11-1.49$ & $1.57^{\mathrm{a}}$ & $1.26-1.95$ & 1.16 & $0.76-1.79$ \\
\hline \multicolumn{7}{|l|}{ Psychosocial factors } \\
\hline Lack of control & $1.29^{a}$ & $1.15-1.45$ & $1.65^{\mathrm{a}}$ & $1.39-1.96$ & 1.32 & $0.95-1.85$ \\
\hline High work demands & 1.07 & $0.95-1.20$ & 1.10 & $0.92-1.31$ & 1.04 & $0.75-1.45$ \\
\hline Lack of support at work & 1.31 & $0.95-1.34$ & $1.30^{\mathrm{a}}$ & $1.02-1.66$ & $1.68^{a}$ & $1.11-2.55$ \\
\hline Dissatisfaction with work & 1.12 & $0.95-1.31$ & $1.46^{\mathrm{a}}$ & $1.02-2.08$ & $2.24^{\mathrm{a}}$ & $1.25-4.01$ \\
\hline
\end{tabular}

a $P<0.05$. 
Table 4. Adjusted rate ratios (RR) and $95 \%$ confidence intervals $(95 \% \mathrm{Cl}$ ) of individual, lifestyle and work-related factors, health indicators, and work ability for sickness absence in a longitudinal study among 5867 male construction workers in the Netherlands. (BMI = body mass index)

\begin{tabular}{|c|c|c|c|c|c|c|}
\hline & \multicolumn{2}{|c|}{$\begin{array}{l}\text { Short spell of sickleave } \\
<2 \text { weeks }(N=1284)\end{array}$} & \multicolumn{2}{|c|}{$\begin{array}{l}\text { Moderate spell of sickleave } \\
2-12 \text { weeks }(\mathrm{N}=547)\end{array}$} & \multicolumn{2}{|c|}{$\begin{array}{l}\text { Long spell of sickleave } \\
>12 \text { weeks }(\mathrm{N}=150)\end{array}$} \\
\hline & $\mathrm{RR}$ & $95 \% \mathrm{Cl}$ & $\mathrm{RR}$ & $95 \% \mathrm{Cl}$ & $\mathrm{RR}$ & $95 \% \mathrm{Cl}$ \\
\hline \multicolumn{7}{|l|}{ Individual characteristics } \\
\hline \multicolumn{7}{|l|}{ Age } \\
\hline$<40$ years & 1.00 & Reference & 1.00 & Reference & 1.00 & Reference \\
\hline $40-50$ years & $0.68^{a}$ & $0.59-0.78$ & 1.24 & $0.96-1.59$ & 1.24 & $0.76-2.02$ \\
\hline$\geq 50$ years & $0.61^{a}$ & $0.53-0.70$ & $1.39^{a}$ & $1.08-1.78$ & 1.55 & $0.96-2.49$ \\
\hline \multicolumn{7}{|l|}{$\mathrm{BMI}\left(\mathrm{kg} / \mathrm{m}^{2}\right)$} \\
\hline Normal weight & 1.00 & Reference & 1.00 & Reference & 1.00 & Reference \\
\hline Overweight & 1.04 & $0.92-1.18$ & 1.09 & $0.89-1.33$ & 1.14 & $0.78-1.66$ \\
\hline Obese & 1.02 & $0.85-1.22$ & $1.34^{\mathrm{a}}$ & $1.02-1.76$ & $1.63^{\mathrm{a}}$ & $1.00-2.63$ \\
\hline \multicolumn{7}{|l|}{ Lifestyle factors } \\
\hline Smoker & $1.14^{\mathrm{a}}$ & $1.01-1.28$ & $1.29^{a}$ & $1.07-1.56$ & 1.16 & $0.81-1.64$ \\
\hline \multicolumn{7}{|l|}{ Work-related physical factors } \\
\hline Manual materials handling & 1.00 & $0.89-1.13$ & $1.38^{a}$ & $1.13-1.68$ & $1.54^{\mathrm{a}}$ & $1.06-2.23$ \\
\hline Awkward back posture & $1.18^{\mathrm{a}}$ & $1.03-1.36$ & 1.12 & $0.90-1.39$ & 0.99 & $0.65-1.50$ \\
\hline \multicolumn{7}{|c|}{ Work-related psychosocial factors } \\
\hline Lack of control & $1.17^{\mathrm{a}}$ & $1.04-1.31$ & $1.44^{\mathrm{a}}$ & $1.20-1.72$ & 1.12 & $0.78-1.59$ \\
\hline \multicolumn{7}{|l|}{ Health indicators } \\
\hline Lung restriction & 1.48 & $0.93-2.35$ & $1.23^{\mathrm{a}}$ & $0.57-2.65$ & $3.20^{\mathrm{a}}$ & $1.19-8.62$ \\
\hline \multicolumn{7}{|l|}{ Work ability index } \\
\hline Excellent & 1.00 & Reference & 1.00 & Reference & 1.00 & Reference \\
\hline Good & $1.49^{a}$ & $1.30-1.70$ & $1.53^{\mathrm{a}}$ & $1.22-1.93$ & 1.46 & $0.93-2.30$ \\
\hline Moderate & $2.10^{\mathrm{a}}$ & $1.75-2.52$ & $2.46^{\mathrm{a}}$ & $1.86-3.25$ & $3.76^{\mathrm{a}}$ & $2.24-6.31$ \\
\hline Poor & 1.65 & $0.94-2.91$ & $2.35^{\mathrm{a}}$ & $1.18-4.68$ & 2.40 & $0.70-8.22$ \\
\hline
\end{tabular}

a $P<0.05$.

of diagnosed diseases, and the physical and mental demands in relation to the job had RR close to unity, when adjusted for the covariates included in the analyses in table 4 .

\section{Discussion}

This study confirmed that sickness absence among Dutch construction workers is a multifactorial phenomenon with individual, lifestyle and work-related factors as important predictors of sickness absence, especially sick leave $>2$ weeks. Predictors for sick leave of 2-12 weeks and $>12$ weeks included: older age, obesity, smoking, manual materials handling, lack of control at work, lung restriction, and a less-than-excellent work ability. For most predictors, higher RR values were observed with a longer duration of sickness absence. Obesity, smoking, manual materials handling, and a lack of job control remained important risk factors for moderate and long durations of sickness absence after adjustment for the strong effects of work ability on sick leave.
Some limitations must be taken into account in this study. First of all, the data were drawn from the voluntary medical examination of workers, and information on non-respondents was not available. We do not know whether we have overestimated due to a larger number of unhealthy workers taking part in the physical examination. A selective participation may have influenced the results of our study, but the potential effect of this source of differential bias is unknown. Secondly, there is a substantial variation in the quality of the laboratory tests and spirometry measurements among the different offices of the occupational health service. A large measurement error could result in a substantial underestimation of the importance of these measurements on future sickness absence.

It has been shown in several studies that younger age is primarily associated with a higher frequency of sickness absence, but that older workers tend to be absent for longer spells (6-9). The effect of age in our study was consistent with these findings, showing that younger age was a risk factor for a short duration of sickness absence, but that moderate and long spells of sick leave occurred more often in older workers. While 
the association between being overweight and sickness absence was not significant, obesity was associated with sickness absence of 2-12 weeks (RR 1.34) and $>3$ months (RR 1.63). In their literature review, Aldana \& Pronk (32) showed that excessive body weight had the strongest association with absenteeism. It has also been shown that obese employees were 1.74 and 1.61 times more likely to experience high and moderate levels of absenteeism, respectively (33). The association between smoking and increased risk of sickness absence confirms the findings of previous studies $(34,35)$. In our study of construction workers with a considerable physical work load, normal and vigorous physical activity during leisure time were not associated with any duration of absenteeism after adjustment for other risk factors. Other studies among samples of the general workforce with less physically strenuous jobs have shown that exercise reduces sick leave over a period of four years (36) and that vigorous physical activity during leisure time for at least three times a week had a positive effect on sick leave (37).

Although white-collar jobs had a strongly reduced probability of any sick leave, we did not include this variable in the multivariate model, since job type was strongly associated with the occurrence of work-related factors, especially factors of physical load. Inclusion of job type as well as physical load factors in the same model caused multicollinearity, with substantially larger confidence intervals for all variables.

The most important work factor that determined moderate and long durations of sick leave was manual materials handling; a lack of job control determined a moderate duration of sick leave only. The effect of physical load on moderate and long spells of sickness absence was consistent with previous reports (38). Uncomfortable working conditions (such as heavy physical work), monotonous movements, and holding a highly physical, demanding job have been shown to be associated with sickness absence $(3,39-43)$. Findings from other prospective studies indicated that stressful working conditions, combined with low decision latitude and low social support at work, were related to sickness absence (44-46). Despite the fact that several studies have investigated the effect of physical and psychosocial factors on absenteeism separately, only a few studies have analyzed the effect of such exposure simultaneously on different durations of sickness absence $(39,47,48)$.

Among the objective health measures, a restrictive pulmonary abnormality, based on spirometry findings, was a predictor for any duration of sickness absence. The effect of a lung restriction was somewhat larger than the effect of lung obstruction (table 2), but, due to the strong association between both respiratory diseases, their relative effect could not be established. In the multivariate analyses, we decided to include lung restriction as the variable with the largest effect in the univariate analysis. The Framingham risk score did not show any significant effect on absenteeism after adjustment. Although subjects with a higher Framingham risk score are at risk for future cardiovascular events, in most cases they did not report any cardiovascular health problems. Therefore, it was unexpected that no association was observed.

Several studies have investigated the predictive value of the WAI on early exit from the work force $(19,21,49)$. The results of this study showed that the WAI predicts sickness absence, especially periods of a longer duration. Although this study was conducted in the construction industry consisting mainly of blue-collar workers who experienced a high physical work load, the results were consistent with a community-based study among the general workforce in Finland which showed that a reduced WAI was a predictor of long-term sickness absence (21). The inclusion of the WAI in the multivariate regression model reduced the influence of physical and psychosocial work-related factors on sick leave. Since it has been shown that up to $22 \%$ of variance in work ability can be attributed to physical and psychosocial factors, these factors also have an indirect effect on sick leave through their influence on the WAI (20). Nevertheless, manual materials handling, and lack of job control remained important risk factors for moderate and long durations of sickness absence after adjusting for the strong effects of work ability on sick leave.

The strong effect of the WAI on sickness absence was primarily due to two dimensions in this index: (i) the presence of sickness absence in the past 12 months prior to the medical examination and (ii) experienced limitations due to health problems. The presence of diagnosed diseases, and the physical and mental demands in relation to the job did not have increased RR when adjusted for other important covariates in the statistical models. The fact that previous sick leave predicted the duration of sickness absence during follow-up is an expected result. It is of interest to note that disease-related job impairments experienced by workers predicted future sick leave, but that the presence of these diseases was not a significant predictor. This finding corroborates a previous study (50) which demonstrated that impairments due to health problems were more important for productivity loss at work than the health problems themselves.

The "illness flexibility model" $(50,51)$ clarifies the complicated relationship between different factors and the decision to either take sick leave or stay at work inspite of illness. All of these factors have prompted many workplaces to create their own procedures to diminish lost work time due to sick leave $(52,53)$. In this regard, it is of interest to note that, for most predictors, a significant trend was observed with higher 
$\mathrm{RR}$ values for a longer duration of sickness absence. This knowledge can be of great help to occupational physicians and policy-makers in enhancing working conditions and health behavior, and consequently reducing their impact on sickness absence. In conclusion, this study suggests that a variety of preventive measures targeted at smoking, obesity, physical load, psychosocial work factors, and work ability will contribute to diminishing the occurrence of sick leave, especially absence of a longer duration.

\section{Acknowledgement}

Dr Seyed Mohammad Alavinia, a PhD student at Netherlands Institute for Health Sciences in Rotterdam, the Netherlands, is supported by a scholarship from the North Khorasan University of Medical Sciences, Bojnord, Iran.

\section{References}

1. Benavides FG. Ill health, social protection, labour relations, and sickness absence. Occup Environ Med. 2006;63:228-9.

2. Niedhammer I, Bugel I, Goldberg M, Leclerc A, Gueguen A. Psychosocial factors at work and sickness absence in the Gazel cohort: a prospective study. Occup Environ Med. 1998;55:735-41.

3. Voss M, Floderus B, Diderichsen F. Physical, psychosocial, and organizational factors relative to sickness absence: a study based on Sweden Post. Occup Environ Med. 2001;58:178-84.

4. Kristensen T. Sickness absence and work strain among Danish slaughterhouse workers: an analysis of absence from work regarded as coping behaviour. Soc Sci Med. 1991;32:15-27.

5. Duijts SF, Kant I, Swaen GM, van den Brandt PA, Zeegers MP. A meta-analysis of observational studies identifies predictors of sickness absence. J Clin Epidemiol. 2007;60:1105-15.

6. Lund T, Labriola M, Villadsen E. Who is at risk for longterm sickness absence? A prospective cohort study of Danish employees. Work. 2007;28:225-30.

7. Eshoj P, Jepsen JR, Nielsen CV. Long-term sickness absence - risk indicators among occupationally active residents of a Danish county. Occup Med (Lond). 2001;51:347-53.

8. Alexanderson K. Sickness absence: a review of performed studies with focused on levels of exposures and theories utilized. Scand J Soc Med. 1998;26:241-9.

9. Marmot M, Shipley M, North F, Syme SL. Sickness absence as a measure of health status and functioning: from the UK Whitehall II study. J Epidemiol Community Health. 1995;49:124-30.

10. Labriola M, Lund T, Burr H. Prospective study of physical and psychosocial risk factors for sickness absence. Occup Med (Lond). 2006;56:469-74.

11. Sharp C, Watt S. A study of absence rates in male and female employees working in occupations of equal status. Occup Med (Lond). 1995;45:131-6.

12. North F, Syme SL, Feeney A, Head J, Shipley MJ, Marmot MG. Explaining socioeconomic differences in sickness absence: the Whitehall II Study. BMJ. 1993;306:361-6.

13. Andrea H, Beurskens AJ, Metsemakers JF, van Amelsvoort LG, van den Brandt PA, van Schayck CP. Health problems and psychosocial work environment as predictors of long term sickness absence in employees who visited the occupational physician and/or general practitioner in relation to work: a prospective study. Occup Environ Med. 2003;60:295-300.

14. Blank N, Diderichsen F. Short-term and long-term sick leave in Sweden: relationships with social circumstances, working conditions and gender. Scand J Soc Med. 1995;23:265-72.

15. Brenner $\mathrm{H}$, Ahern W. Sickness absence and early retirement on health grounds in the construction industry in Ireland. Occup Environ Med. 2000;57:615-20.

16. Peterson JS, Zwerling C. Comparison of health outcomes among older construction and blue-collar employees in the United States. Am J Ind Med. 1998; 34:280-7.

17. Elders LAM, Heinrich J, Burdorf A. Risk factors for sickness absence because of low back pain among scaffolders: a 3-year follow-up study. Spine. 2003;28:1340-6.

18. Burkhart C, Schulte PA, Robinson C, Sieber WK, Vossenas P, Ringen K. Job tasks, potential exposures, and health risks of laborers employed in the construction industry. Am J Ind Med. $1993 ; 24: 413-25$.

19. Tuomi K, Huuhtanen P, Nykyri E, Ilmarinen J. Promotion of work ability, the quality of work and retirement. Occup Med (Lond). 2001;51:318-24.

20. Alavinia SM, van Duivenbooden C, Burdorf A. Influence of work-related factors and individual characteristics on work ability among Dutch construction workers. Scand J Work Environ Health. 2007;33(5):351-7.

21. Kujala V, Tammelin T, Remes J, Vammavaara E, Ek E, Laitinen J. Work ability index of young employees and their sickness absence during the following year. Scand J Work Environ Health. 2006;32(1):75-84.

22. Karasek R, Brisson C, Kawakami N, Houtman I, Bongers P, Amick B. The Job Content Questionnaire (JCQ): an instrument for internationally comparative assessments of psychosocial job characteristics. J Occup Health Psychol. 1998;3:322-55.

23. Health Council of the Netherlands. Guidelines for a healthy diet 2006. The Hague: Health Council of the Netherlands; 2006. Publication no 2006/21.

24. Pate RR, Pratt M, Blair SN, Haskell WL, Macera CA, Bouchard C, et al. Physical activity and public health: a recommendation from the Centers for Disease Control and Prevention and the American College of Sports Medicine. JAMA. 1995;273:402-7.

25. Stocks J. Quanjer PH. Reference values for residual volume, functional residual capacity and total lung capacity: 
ATS Workshop on Lung Volume Measurements: Official Statement of The European Respiratory Society. Eur Respir J. 1995;8:492-506.

26. Pellegrino R, Viegi G, Brusasco V, Crapo RO, Burgos F, Casaburi $\mathrm{R}$, et al. Interpretative strategies for lung function tests. Eur Respir J. 2005;26:948-68.

27. Executive summary of the Third Report of The National Cholesterol Education Program (NCEP) Expert Panel on Detection, Evaluation, And Treatment of High Blood Cholesterol In Adults (Adult Treatment Panel III). JAMA. 2001;285:2486-97.

28. Greenland P, LaBree L, Azen SP, Doherty TM, Detrano RC Coronary artery calcium score combined with Framingham score for risk prediction in asymptomatic individuals. JAMA. 2004;291:210-5

29. Tuomi K, Ilmarinen J, Jahkola A, Katajarinne L, Tulkki A. Work ability index. 2nd ed. Helsinki: Finnish Institute of Occupational Health; 1998. Occupational Health Care 19.

30. Christensen KB, Andersen PK, Smith-Hansen L, Nielsen ML, Kristensen TS. Analyzing sickness absence with statistical models for survival data. Scand J Work Environ Health. 2007;33(3):233-9.

31. Pearce N, Checkoway H, Dement J. Exponential models for the analysis of time-related factors, illustrated with asbestos textile worker mortality data. J Occup Med. 1988;30:517-22.

32. Aldana SG, Pronk NP, Health promotion programs, modifiable health risks, and employee absenteeism. J Occup Environ Med. 2001;43:36-46.

33. Tucker LA, Friedman GM. Obesity and absenteeism: an epidemiologic study of 10,825 employed adults. Am J Health Promot. 1998;12:202-7.

34. Christensen KB, Lund T, Labriola M, Bültmann U, Villadsen E. The impact of health behaviour on long term sickness absence: results from DWECS/DREAM. Ind Health. 2007;45:348-51.

35. Sindelar JL, Duchovny N, Falba TA, Busch SH. If smoking increases absences, does quitting reduce them? Tobacco Control. 2005;14:99-105.

36. van den Heuvel SG, Boshuizen HC, Hildebrandt VH, Blatter BM, Ariëns GA, Bongers PM. Effect of sporting activity on absenteeism in a working population. Br J Sports Med. 2005;39:e15.

37. Proper KI, van den Heuvel SG, De Vroome EM, Hildebrandt VH, Van der Beek AJ. Dose-response relation between physical activity and sick leave. Br J Sports Med. 2006; $40: 173-8$.

38. Ekberg K, Wildhagen I. Long-term sickness absence due to musculoskeletal disorders: the necessary intervention of work conditions. Scand J Rehabil Med. 1996;28:39-47.

39. Lund T, Labriola M, Christensen KB, Bültmann U, Villadsen E. Physical work environment risk factors for long term sickness absence: prospective findings among a cohort of 5357 employees in Denmark. BMJ. 2006;332:449-52.

40. Hoogendoorn WE, Bongers PM, de Vet HC, Ariëns GA, van Mechelen W, Bouter LM. High physical work load and low job satisfaction increase the risk of sickness absence due to low back pain: results of a prospective cohort study. Occup Environ Med. 2002;59:323-8

41. Boedeker W. Associations between workload and diseases rarely occurring in sickness absence data. J Occup Environ Med. 2001;43:1081-8.

42. Trinkoff AM, Storr CL, Lipscomb JA. Physically demanding work and inadequate sleep, pain medication use, and absenteeism in registered nurses. J Occup Environ Med. 2001;43:355-63.

43. Houtman ILD, Bongers PM, Smulders PGW, Kompier MAJ Psychosocial stressors at work and musculoskeletal problems. Scand J Work Environ Health. 1994;20:139-45.

44. Head J, Kivimäki M, Martikainen P, Vahtera J, Ferrie JE, Marmot MG. Influence of change in psychosocial work characteristics on sickness absence: The Whitehall II Study. J Epidemiol Community Health. 2006;60:55-61.

45. Stansfeld S, Head J, Ferrie J. Short-term disability, sickness absence, and social gradients in the Whitehall II Study. Int J Law Psychiatry. 1999;22:425-39.

46. Melchior M, Niedhammer I, Berkman LF, Goldberg M Do psychosocial work factors and social relations exert independent effects on sickness absence? A six year prospective study of the GAZEL cohort. J Epidemiol Community Health. 2003;57:285-93.

47. Väänänen A, Toppinen-Tanner S, Kalimo R, Mutanen P, Vahtera J, Peiró JM. Job characteristics, physical and psychological symptoms, and social support as antecedents of sickness absence among men and women in the private industrial sector. Soc Sci Med. 2003;57:807-24.

48. Devereux JJ, Vlachonikolis IG, Buckle PW. Epidemiological study to investigate potential interaction between physical and psychosocial factors at work that may increase the risk of symptoms of musculoskeletal disorder of the neck and upper limb. Occup Environ Med. 2002;59:269-77.

49. Tuomi K, Ilmarinen J, Klockars M, Nygård C-H, Seitsamo J, Huuhtanen $\mathrm{P}$, et al. Finnish research project on aging workers in 1981-1992. Scand J Work Environ Health. 1997;23 suppl $1: 7-11$

50. Alavinia SM, Molenaar D, Burdorf A. Productivity loss in the workforce: associations with health, work demands, and individual characteristics. Am J Ind Med. 2009;52:49-56.

51. Johansson G, Lundberg I. Adjustment latitude and attendance requirements as determinants of sickness absence or attendance: empirical tests of the illness flexibility model. Soc Sci Med. 2004;58:1857-68.

52. Hansson M, Bostrom C, Harms-Ringdahl K. Sickness absence and sickness attendance - what people with neck or back pain think? Soc Sci Med. 2006;62: 2183-95.

53. Martimo K-P. Reducing sickness absenteeism at the workplace - what to do and how? [editorial]. Scand J Work Environ Health. 2006;32(4):253-5.

Received for publication: 20 February 2008 